Paisaje y trance en tres obras de la narrativa latinoamericana contemporánea

\title{
PAISAJE Y TRANCE EN TRES OBRAS DE LA NARRATIVA LATINOAMERICANA CONTEMPORÁNEA ${ }^{1}$
}

\author{
Andrea Estefanía Álvarez Orozco \\ Universidad del Quindío / Universidad Tecnológica de Pereira (Colombia) \\ aealvarez@uniquindio.edu.co \\ Juan Manuel Acevedo Carvajal \\ Universidad del Quindío (Colombia) / Universidad Andina Simón Bolívar (Ecuador) \\ jmacevedo@uniquindio.edu.co \\ Hugo Mario Ruiz Cárdenas \\ Universidad del Quindío (Colombia) \\ hruiz@uqvirtual.edu.co
}

Recibido: 26/01/2020 - Aprobado: 08/06/2021 - Publicado: 30/07/2021

DOI: doi.org/10.17533/udea.lyl.n80a09

\begin{abstract}
Resumen: En este artículo se presentan las reflexiones de Jens Andermann sobre el paisaje y el trance, mediante las novelas Distancia de rescate (2015), El diablo de las provincias (2017), y De ganados y de hombres (2015). Narraciones que están situadas en una tradición literaria en la que el paisaje ya no es la metrópoli latinoamericana, sino el retorno al paisaje oculto que había sido desligado de la vida en las ciudades, y expulsado de los relatos en la proliferación de novelas urbanas que ocuparon gran parte de las ficciones de finales del siglo Xx e inicios del XXI en Latinoamérica.
\end{abstract}

Palabras clave: paisaje; trance; biopoder; selva; rural.

\section{LANDSCAPE AND TRANCE IN THREE WORKS OF CONTEMPORARY LATIN AMERICAN NARRATIVE}

Abstract: This article presents the reflections of Jens Andermann on the landscape and the trance, through the novels Distancia de rescate (2015), El diablo de las provincias (2017), and De ganados y de hombres (2015). Narrations that are located in a literary tradition in which the landscape is no longer the Latin American metropolis, but the return to the hidden landscape that had been detached from life in the cities, and expelled from the stories in the proliferation of urban novels that occupied much of the fictions of the late twentieth century and early twenty-first century in Latin America.

Key words: landscape; trance; biopower; jungle; rural.

1. El presente artículo se deriva de la investigación Estética del Desvarío en la Narrativa Latinoamericana Contemporánea, del grupo de investigación en Literaturas Marginales Marginalia, del programa de Licenciatura en Literatura y Lengua Castellana de la Universidad del Quindío.

Editores 


\section{Introducción}

No hay naturaleza, sólo sus efectos Jacques Derrida

El paisaje es el archivo fisico donde están trazadas las relaciones sociales de la naturaleza

Jens Andermann

$\mathbf{J}$ ens Andermann, en su libro Tierras en trance. Arte y naturaleza después del paisaje (2018), investiga los modos de articulación del paisaje y la naturaleza con el arte latinoamericano. En el libro, Andermann define el trance como «aquello que [...] vuelve a ensamblar en el inconsciente, el espacio y el tiempo del sujeto y la comunidad escindidos por una violenta historia de desplazamiento y rupturas temporales» (Andermann, 2018 , p. 22). Esta violenta historia a la que hace referencia tiene su origen en la expansión europea del siglo XVI y la destrucción de otras formas de experimentar el tiempo y el espacio por el modo de producción capitalista, particularmente el reordenamiento del entorno para la extracción intensificada de recursos. Además, el autor hace una crítica del proyecto de economía extractivista y agropecuario en América Latina y su continuación como modernización neoliberal en el presente. En esa vía, afirma que el paisaje necesariamente externalizaría la violencia que constituye su objeto, generando la representación utópica de un espacio-tiempo más allá del capital en el que la acumulación se presenta como infinita. Esta forma de configuración de la violencia en la naturaleza - a veces no explícita y de paso su representación - es el dispositivo que opera, como una forma de recuperación de las literaturas regionales o las literaturas de la selva que abrieron las narraciones en la modernidad latinoamericana. Esto quiere decir que, en medio de estas circunstancias hay un retorno directo, palpable a la selva, donde el delirio aparece y se vuelve evidente sobre todo por la relación de los personajes con esas zonas de excepción del capitalismo de corte neoliberal en las que, como dice Andermann: «se funda y desfonda el régimen de acumulación» (Andermann, 2018, p. 22). Bajo estas condiciones, no hay lugar a distinciones o variaciones destacables entre los países de América Latina. Si bien en este caso, son tres los ejemplos, tres naciones som las moduladas por las narraciones, en las cuales ni el producto ni los mecanismos son exclusivos de cada país mencionado; por ejemplo, los problemas de la carne son fundantes en la tradición argentina, pero en este caso aparecen en una novela del Brasil; la esclavitud de los ingenios y sus herencias no son exclusivas de Colombia y podrían situarse en cualquier otro país de la región. Dicho de otro modo, las relaciones entre capitalismo extractivo y la situación político-económica que han configurado a América Latina comparten rasgos comunes 
Paisaje y trance en tres obras de la narrativa latinoamericana contemporánea

y no diferenciados, debido a que tanto la huella estructural de la extracción y destrucción del paisaje como la acumulación del capital pueden ser verificables desde la Colonia de forma sistémica entre países. En este estudio, estas zonas de excepción son verificables, entre muchas otras existentes, tres narraciones que trazan caminos paralelos y continuos con las literaturas señaladas por Andermann, que están situadas en la modernidad tardía latinoamericana y se imbrican a partir de tres novelas: Distancia de rescate (2015) de Samanta Schweblin, El diablo de las provincias (2017) de Juan Cárdenas, y De ganados y de hombres (2015) de Ana Paula Maia. Narraciones que, además de compartir un espacio temporal «cercano», están situadas en una tradición literaria en la que el paisaje ya no está determinado por la metrópoli latinoamericana y el devenir de los personajes allí ni el deambular introspectivo y gastado de los individuos en ella, sino el retorno a las provincias, a los campos , al paisaje oculto que había sido desligado de la vida en la ciudades expulsado de las historias en la proliferación de novelas urbanas que ocuparon gran parte de relatos de finales del siglo xx y los primeros del siglo xxI en Latinoamérica. En concreto, estas historias se encuentran ligadas a las afectaciones que ejerce el capital en el paisaje, y de ahí sus efectos delirantes, como en Los campos de soja del norte de Argentina, las relaciones entre la violencia política y la instalación de los diversos tipos de monocultivos en Colombia (caucho, café, palma, hoja de coca y otros) y la ganadería extensiva en el Brasil, actividades que traen como consecuencia la dislocación de los ecosistemas y las alteraciones climáticas, que generan, además, una trama de violencias que sostienen la destrucción del paisaje y que permiten la libre circulación de las mercancías derivadas de estas formas de economía sin ningún tipo de regulación legal.

\section{Enfermedades tóxicas en Distancia de rescate}

Dicho lo anterior, en este excurso aparecen las tres narraciones, cuyo motor delirante se identifica en la explotación descontrolada de la naturaleza, en lugares caracterizados por ser fuente de toda pesadilla. La primera de ellas es Distancia de rescate (2015), de la escritora argentina Samanta Schweblin, en la cual la autora sigue una corriente de la narrativa latinoamericana en la que la inocencia del paisaje queda despojada de todo el espacio decorativo que la mirada colonial presenta sobre este. La novela tiene un falso corsé de terror, de tragedia familiar; una mujer, Amanda, y su hija, Nina, pasan unos días en una casa de campo, en un pueblo del interior de la provincia de Buenos Aires, que está rodeada de cultivos de soja. La casa es alquilada a Carla, una mujer, quien es madre de David, un niño que será intoxicado al tomar agua de un arroyo. En lo que funciona como un ejercicio de reconstrucción y fantasía, la narración se arma desde una conversación posible y futura entre Amanda, que está en una camilla de enfermería, y David, quien ha perdido parte de su alma luego de haberse intoxicado. Un relato contado por esas dos voces y con ausencia absoluta del narrador omnisciente. El enlace de esta conversación trata de desnudar lo ocurrido con Nina, y por qué Amanda, a pesar de la cercanía con su hija, no la pudo salvar. Esta trama compleja que pivota sobre la idea del tiempo de rescate que una madre puede tener con su hija, de 


\section{Paisaje y trance en tres obras de la narrativa latinoamericana contemporánea}

ese hilo parental que las une, muestra cómo en su interior la posibilidad de rescate se ve asaltada por los efectos contaminantes de una naturaleza que está sumergida por alteraciones imperceptibles, pero que modifican con su presencia fantasmática el destino de los personajes. Todo esto aparece en pequeños indicios diseminados en la reconstrucción de los eventos que se perciben como fugas respecto al relato central. Es así como se hace mención en varias ocasiones de la obra a la intoxicación o a la soja y, sobre todo, a los gusanos, palabra que abre la narración y representa toda una declaración de intenciones, una advertencia implícita de lo que acontecerá más adelante, como se aprecia en la conversación repentina entre David y Amanda:

Son como gusanos.

¿Qué tipo de gusanos?

Como gusanos, en todas partes.

El chico es el que habla, me dice las palabras al oído. Yo soy la que pregunta. ¿Gusanos en el cuerpo?

Sí, en el cuerpo.

¿Gusanos de tierra?

No, otro tipo de gusanos.

Está oscuro y no puedo ver. Las sábanas son ásperas, se pliegan debajo de mi cuerpo. No me puedo mover, digo.

Por lo gusanos. Hay que ser paciente y esperar. Y mientras se espera hay que encontrar el punto exacto en el que nacen los gusanos.

¿Por qué?

Porque es importante, es muy importante para todos (Schweblin, 2015, p. 11).

Como se puede leer, entonces, la conversación está anudada por los gusanos, por la omnipresencia de estos insectos, que no son habituales y que están pegados a un cuerpo. Sin embargo, es el origen de estos bichos a lo que se busca dar respuesta en esta trama: ¿Por qué son importantes los gusanos? ¿Qué relación de terror subyace en la presencia de estos? Los gusanos, en una reinterpretación de su sentido original, son el enlace en la narración, aunque estos sean considerados «invisibles» en gran parte de la novela; es decir, la historia plantea como cuestión de fondo las relaciones entre madres e hijos, y el peligro que circula si estas se rompen, al tiempo que se advierte que lo realmente importante es otra cosa, algo que va a irrumpir, que lo está condicionando todo, que retuerce el discurso narrativo. En este punto, las lecturas que hace Jens Andermann en Tierras en trance (2018) sobre los temas ambientalistas, a partir de la representaciones literarias y artísticas, son fundamentales para entender cómo se articulan, no solo los temas ambientales, sino otros discursos, como el biopolítico, ecológico y el ecocrítico, en el que los ecosistemas o paisajes son vistos en su conjunto, anudados a algunas de las divergencias que existen entre la crítica y la teoría. De acuerdo con Andermann, en América Latina los efectos del avance capitalista ejercen violencias sobre el sujeto y su paisaje habitado y sus medios de representación, señalando cómo algunas literaturas latinoamericanas de mediados del siglo xx representaron puntos límite que ponen en riesgos el régimen biopolítico de la vida. En esa vía, uno de los tantos modos de operación que es explicado por el autor, lo señala cuando habla de la naturaleza insurgente, refiriéndose al cuento de Horacio Quiroga «El simún». Quiroga, como se sabe, fue un escritor que construyó una narrativa atravesada por el impacto que causó la modernidad de las primeras décadas del siglo pasado en el subcontinente americano. A partir de esto, el escritor estadounidense 


\section{Paisaje y trance en tres obras de la narrativa latinoamericana contemporánea}

toma este cuento como una reflexión iniciática — en los territorios latinoamericanos - sobre las relaciones entre ambiente y cuerpo que surgen de la contraposición entre estas con la naturaleza. Si bien la naturaleza narrada por Quiroga es «otra», está anclada a otro tiempo con respecto a la narrada por Schweblin, ya que los procedimientos narrativos de uno y otro riman, son similares. Puede notarse cómo en ambos casos los territorios son zonas de contacto donde se negocia el régimen biopolítico de la vida. En este retorno al paisaje natural como lugar de operaciones marcado en Distancia de rescate que ha sido alterado en el proceso violento de modernización, ya no se nota una naturaleza que ofrece resistencia, sino a una que ha sido modificada por otras formas de organización y control político-económico. De este modo, retomando el discurso de Andermann, «El simún» es un texto que señala un esquema de «insurgencias» ambientales:

«El simún» es un texto umbral, texto que abre y establece el escenario de una literatura que está aún por venir y de la cual la obra del propio Quiroga, en particular sus cuentos misioneros, representará una parte no menor: una serie de «insurgencias» ambientales a cuyo estallido violento corresponderá un quiebre o desdoblamiento al interior del propio discurso narrativo (Andermann, 2018, p. 177).

A partir de esta interpretación, cabe plantear y dar respuesta a los siguientes cuestionamientos frente al trasfondo de Distancia de rescate: ¿cuál es la serie de insurgencias ambientales? ¿cómo se desdobla esta el interior del discurso? ¿de qué manera engendran las composiciones delirantes? Como se ha dicho, hay una serie de menciones que circundan la trama inicial, que son nombradas y remarcadas por una amenaza latente: la intoxicación, que es la fuente de todos los acontecimientos de la historia. Esto puede constatarse en la reconstrucción que se hace en la búsqueda de los gusanos, cuando David y el caballo de Omar, el esposo de Carla, caen enfermos: «El caballo ya está muerto» (Schweblin, 2015, p. 26); «Es una intoxicación» (p. 26); «va a atacarle el corazón» (p. 26). Entonces, ¿cuál es el origen de estas intoxicaciones? En primer lugar, cabe señalar que la naturaleza no es descrita en la novela como un campo agreste o un ecosistema diverso, sino como, un espacio insustancial, alterado, sin aparente importancia, pues el espacio rural en el que se encuentran los personajes es en realidad un extenso campo de cultivos de soja «verdes y brillantes», en apariencia anodinos. Los sembradíos son, así, el «monstruo» en sus entrañas, aunque las plantaciones no representen, en apariencia, peligro alguno. A continuación, se ofrece una descripción de estos campos:

Hacia este lado las casas tienen mucho más terreno. Algunas hasta tienen sembrados, los lotes alargados se extienden hacia el fondo hasta la media hectárea, unos pocos con trigo o girasoles, casi todos con soja (Schweblin, 2015, p. 45).

Sabiendo esto, Lo que ocurre en realidad es una relación contaminante de las fuentes hídricas que circulan por los campos. Esto es lo que ocurre, luego de darse la intoxicación de David y el caballo, relatado por la madre del chico:

-David se había acuclillado en el riachuelo, tenía las zapatillas empapadas, había metido las manos en el agua y se chupaba los dedos. Entonces vi el pájaro muerto. Estaba muy cerca, a un paso de David. Le grité asustada, y él se 


\section{Paisaje y trance en tres obras de la narrativa latinoamericana contemporánea}

asustó también, se levantó enseguida y se cayó de culo del mismo susto. Mi pobre David. Me acerqué arrastrando el caballo, que relinchaba y no quería seguirme, y como pude me las ingenié para cargarlo con una sola mano y luchar con los dos para trepar hasta arriba (Schweblin, 2015, p. 20).

En esta escena, David y el caballo toman el agua de un riachuelo que pasa por la casa. En este caso, el hecho de estar rodeados en un campo de soja aporta suficientes indicios para determinar que el agua del riachuelo es uno de los vehículos contaminantes. Esta es una muestra de cómo el ecosistema alterado puede ser el origen de fuentes delirantes. De este modo, lo que parece ser un cultivo de soja anodino, es en realidad un ambiente rural lleno de conflictos. Al respecto, Lapolla, (2007), detectó en su investigación lo siguiente:

Los que recorremos la «pampa sojera», recogemos denuncias en todas las localidades visitadas, sobre un fuerte incremento de casos de cáncer, malformaciones, alergias de todo tipo, así como enfermedades autoinmunes y «raras», que afectan a los pobladores — especialmente niños y mujeres - sometidos a los efectos de las fumigaciones realizadas en masa en las cercanías o directamente sobre los poblados. Esto es así en poblados de Córdoba, como Pueblo Italiano, Río Ceballos, Saldán, Alto Alberdi, Jesús María, Colonia Caroya, Sacanta y en varios barrios de la propia Ciudad de Córdoba, además del emblemático caso de Barrio Ituzaingó (§ 6).

Este es el campo rural, una pampa sojera, en la cual no solo se cultiva soja, sino que se «cultivan» enfermedades que afectan a la población. Enfermedades tóxicas que alteran los cuerpos de los pobladores. Toda esta serie de consecuencias derivadas de las fumigaciones con glifosato en los campos. Además, en su estudio, Lapolla cita otras investigaciones donde se establece una relación entre el desarrollo de enfermedades entre los pobladores de las zonas donde se cultiva la soja y la utilización de máquinas de fumigación y agrotóxicos en dichas áreas:

Un estudio multidisciplinario llevado adelante por el Centro de Investigaciones en Biodiversidad y Ambiente (Ecosur), el Hospital Italiano Garibaldi de Rosario, la Universidad Nacional de Rosario, el INTA, el Colegio de Ingenieros Agrónomos y la Federación Agraria Argentina, comprobó fuertes correlaciones entre los casos de cáncer, leucemia, lupus y otras graves afecciones, halladas en seis pequeños pueblos del área Sur y central sojera de Santa Fe, con la localización de las máquinas de fumigación, depósitos de agrotóxicos, «silos» de bidones de plaguicidas, transformadores eléctricos con PCB, y lugares de frecuentes fumigaciones aéreas y «chorreado» de los tanques de los aviones aspersores (Lapolla, 2007, § 8).

Todos estos factores coinciden con los que aparecen descritos a lo largo de la narración de Schweblin, tomando por caso el siguiente: «David se acercó otra vez y me abrazó. Tenía los ojos hinchados, los párpados rojos y tirantes, inflados como los del caballo» (Schweblin, 2015, p. 29). Otra de las referencias al respecto se hace en el momento en el que un grupo de hombres descarga un camión con los bidones y uno de estos queda expuesto, siendo además una señal de «lo importante», como pasó con los gusanos:

Afuera los hombres bajan bidones, son grandes y apenas pueden con uno en cada mano. Hay muchos, todo el camión está lleno de bidones.

-Es esto.

-Uno de los bidones quedó solo en la entrada del galpón.

-Esto es lo importante. 
—Esto es lo importante?

一Sí.

— ¿Cómo puede ser esto lo importante? (Schweblin, 2015, p. 62).

Y es ese momento «importante» donde aparece el núcleo completo de lo que ha sucedido, pues se imbrican todos los indicios señalados; «lo importante», los pesticidas, la rotura del hilo que une el tiempo de rescate, la tragedia derivada del delirio ambiental. Todo en este punto gira y sucede sin muchas posibilidades de hacer algo ante la amenaza no visible, ya que, en la narración, justo cuando los hombres terminan de descargar el camión y todo el entorno parece apacible, una tarde de campo, unos hombres trabajan y una madre observa con su hija, Nina, el horror, la tragedia, «lo importante», que, aunque no de una manera evidente, sucede ante ellas:

Estamos muy cerca de todo, en el medio de todo, casi molestando, pero las cosas suceden lentas y amables, los hombres son agradables y sonríen a Nina una y otra vez. Cuando los hombres terminan de bajar los bidones, saludan al conductor y el camión se va. Los hombres vuelven a entrar a la casa, y nosotras nos levantamos del pasto. Yo miro el reloj y son las nueve menos cuarto. Entre una cosa y otra hace rato que empezó el día. Nina se mira la ropa, gira para verse la cola, las piernas.

— ¿Por qué? ¿Qué pasa?

— ¿Qué pasa? - le pregunto-.

- Estoy empapada — dice con algo de indignación-.

-A ver...la tomo de la mano y la hago girar.

-El color de la ropa no ayuda a ver qué tan mojada está, pero la toco y sí, está húmeda.

-Es el rocío - le digo-, ahora con la caminata se seca.

-Es esto. Este es el momento.

- No puede ser, David, de verdad no hay más que esto.

-Así empieza (Schweblin, 2015, p. 64).

Y se confirma unas líneas más adelante:

-Está pasando.

— ¿Qué cosa, David? Dios mío, ¿qué es lo que está pasando?

-Los gusanos (Schweblin, 2015, p. 65).

\section{Paisaje delirante en El diablo de las provincias}

La segunda narración que aparece en esta constelación utiliza modos de representación más directos, a veces subrayados, incluso frontalmente panfletarios. Se hace referencia a El diablo de las provincias (2017), del escritor colombiano Juan Cárdenas. En la novela, que se lee como un retorno hacia los territorios rurales del suroccidente colombiano, un biólogo — sin nombre — vuelve a casa después de 15 años de un exilio voluntario en Europa. A su regreso, en lo que es un deambular espectral y delirante, el hombre se enfrenta con su pasado: el de un hermano homosexual asesinado, el encuentro espeluznante con una exnovia que tiene una pierna amputada, la historia de un díler (traficante de drogas), el relato de un colegio femenino en el que matan señoritas, y el testimonio de 


\section{Paisaje y trance en tres obras de la narrativa latinoamericana contemporánea}

niñas embarazadas que dan luz a bebés «de rostro peludito» y «con palpables bolitas duras en la cabeza». En una de las secuencias de este extravío, el biólogo de El diablo de las provincias está en una antigua hacienda de caña, que ahora es un balneario y alberga una reunión de herederos burgueses que planean desde allí nuevas actividades, como la realización de una telenovela. Estando en el lugar, el biólogo, luego de encontrarse con su exnovia, estudia el ofrecimiento de una propuesta de trabajo que esta le hace. El ofrecimiento consiste en ayudarla a controlar una plaga en un monocultivo de palma africana:

$\mathrm{Su}$ antigua novia estaba dirigiendo un proyecto de investigación sobre el escarabajo picudo, la plaga de palma africana o palma de aceite, un auténtico dolor de cabeza para la economía del sector agrícola. El biólogo ni siquiera había oído hablar de un bicho con ese nombre, pero le bastó con la explicación de la mujer para hacerse una idea de lo que estaba sucediendo. El monocultivo de la palma, que en la última década y media se había vuelto extensivo en toda el área del Pacífico, una plaga en sí mismo, era el ecosistema idóneo para favorecer la propagación de otra plaga: el picudo, un coleóptero proveniente de Asia que pone sus huevos en el interior de las palmas (Cárdenas, 2017, p. 84).

En la información que recibe el biólogo no solo se reconoce en el «picudo» (Rhynchophorus palmarum) la plaga, sino que también se reconoce en el monocultivo la otra plaga. Lo que se advierte en la narración es una trasformación del paisaje «natural» por uno artificial que solo beneficia las economías de extracción con su expansión. A partir de ese punto, el biólogo se pregunta si la plaga es el insecto o la planta, ya que, en el retorno a su ciudad de origen (Popayán, Cauca), es un espacio que también está siendo transformado por la instalación de viviendas: "Luego salió de la pieza a puntas de pie y con esfuerzo reconoció el resto del apartamento, un apartamento chico, uno de esos bloques de vivienda social que se estaban regando por todo el país como cualquier otro monocultivo» (Cárdenas, 2017, p. 49). Contrario a lo que pasa en Distancia de rescate, las referencias al paisaje son más explícitas y están construidas de un modo directo. Dicho de otra manera, la noción de «naturaleza insurgente» que expone Andermann, gravita en esta segunda novela, entre el desarrollo capitalista y las maquinarias coloniales heredadas, que son en mayor medida verificables en el relato. La referencia directa a una antigua hacienda de caña, otrora campo de explotación del paisaje, y punto de esclavitud de cuerpos, es uno de los tantos indicios. Sin embargo, ahora la hacienda es el satélite del comercio del monocultivo de palma en el Pacífico colombiano. Todo esto en relación con la figura del biólogo, visto como supuesto agente de revolución ecológica, ya que hay una amenaza al nuevo paisaje que se está organizando.

Como ha sido documentado por Lizcano (2018), los monocultivos de palma se usan para producir biocombustible y otros productos derivados; no obstante, la siembra de estos desde los años noventa ha cambiado el paisaje reemplazándolo por otro, alterando los ecosistemas y propiciando la propagación de plagas en las regiones de Colombia donde ocurre la novela de Cárdenas (el suroccidente de Colombia, el gran Cauca). En estos territorios, además, las corporaciones que controlan los cultivos han estado involucradas en la guerra interna y en el robo de tierras, en el desplazamiento de comunidades y asesinatos a líderes sociales. Es por eso que, como se ha mencionado, la hacienda de caña es una prolongación de las actividades coloniales y de los agentes de poder que ejercen el dominio de los territorios violentamente. Como pasa en las demás novelas de Juan Cárdenas 
Paisaje y trance en tres obras de la narrativa latinoamericana contemporánea

—Ornamento (2015), Los estratos (2013), Zumbido (2010) y Elástico de sombra (2019)—, los personajes se desprenden de un tipo de orden social establecido para entrar en espacios que se perciben como delirantes. En el caso de El diablo de las provincias, dichos espacios están representados en el paisaje «delirante» de los monocultivos y la relación con el poder político heredado y la violencia subyacente que sostiene ese poder, algo que sabe el biólogo de forma directa, pues él mismo lo reconoce al lograr interrelacionar la muerte de su hermano, el nacimiento de los niños peludos y la propagación de los los monocultivos: «Todo hervía en un mismo dibujo: las emociones, y las ideas, los datos, los recuerdos del tío, un bebé con la cara peluda, la prótesis de una pierna, el asesinato de su hermano, un monocultivo de edificios» (Cárdenas, 2017, p. 114). En esa dirección, muchos de estos delirios, además, se asemejan a momentos de magia o de brujería, en los que las plantas parecen tener voluntad y poder:

Y el biólogo se escabulle entre las cañas sin tiempo, náufrago de otro naufragio más grande, uno que tiene que ver con el tiempo inhumano de las plantas que desean prescindir de todas las demás plantas, las gramíneas hipertrofiadas que quieren dominar el mundo, algunas especies de plantas, entiende el biólogo, son la verdadera bestia del apocalipsis, el pasto nacional-socialista, la caña de azúcar de los esclavos que ya no tienen tiempo, el plátano, que no es más que una hierba gigantesca, la palma de aceite, el pasto está conspirando desde hace milenios para apoderarse del mundo y nos está usando a nosotros como esclavos (Cárdenas, 2017, pp. 89-90).

Lo anterior indica que el paisaje no es solo un campo devastado que es reemplazado por otro, sino que con las alteraciones que sufre somete, en su desastre, a los humanos que creen usarlo, pero en realidad son ellos — los campos, como dice el biólogo en su delirio-, los que están conspirando en favor de la restauración del planeta. Aunque lo que se advierte es la mutilación del ecosistema dando prevalencia a una de las especies, es una operación que, como la describe el biólogo, no es fortuita, pues en realidad representa la extensión de una dominación cíclica. Esta advertencia, producto de las elucubraciones del biólogo, es una de las consecuencias de destrucción a las que son sometidos los paisajes en beneficio de las economías extractivas, es decir, la huella de las vejaciones, la mutación de los paisajes y de los hombres. Esto puede reflejarse en las palabras de Andermann, «El paisaje es el archivo físico donde están trazadas las relaciones sociales de la naturaleza» (2008, p. 5). En la narración de Cárdenas se rompe, también, la dicotomía entre los hombres y el paisaje que, en este caso, ha colapsado por los métodos usados por el capitalismo de extracción. Una paradoja de estas actividades, quizás la primera como antecedente narrativo, es recuperada por Andermann cuando escribe sobre La vorágine (1924), la novela de José Eustasio Rivera. En un tramo de la narración, los jornaleros que deben reducir el ecosistema selvático a un material exportable son consumidos por este, y ellos terminan reducidos y amalgamados con la naturaleza en iguales condiciones. Los jornaleros terminan siendo una nueva presa, en algo que describe Andermann, de la siguiente manera:

Porque, paradójicamente, los jornaleros, quienes, en los obrajes santiagueños como en las caucherías del río Putumayo o de las Guayanas, deben «reducir» el ecosistema selvático a materia exportable, son, ellos mismos «reducidos» a un estado «vegetativo» que se confunde con el de su presa. Como exclama Clemente Silva, el viejo cauchero, 
Paisaje y trance en tres obras de la narrativa latinoamericana contemporánea

quien guía a Arturo Cova por el infierno del Putumayo en La Vorágine: «Mientras le ciño el tronco goteante el tallo acanalado del caraná, para que corra hacia la tazuela su llanto trágico, la nube de mosquitos que lo defiende chupa mi sangre y el vaho de los bosques me nubla los ojos. ¡Así el árbol y yo, con tormento vario, somos lacrimatorios ante la muerte y nos combatiremos hasta sucumbir!» (Andermann, 2018, p. 182).

En el caso de la novela de Cárdenas, como una suerte de contrapunto a lo descrito por Rivera, la rotura también se da entre los hombres esclavos, aquellos que fueron usados para trabajar las tierras, que ahora en la visión del biólogo han mutado en una especie de robots, hombres robots, despojados de toda identidad, adheridos al paisaje uniforme. Individuos sin tiempo que deambulan por la hacienda, mientras él los ve fundirse con los monocultivos, en lo que no se sabe si es un sueño o una visión real. Son dos negros esclavizados, bien vestidos, que pasean y dicen frases hechas, como un virus informático, seguidos por el biólogo hasta perderles el rastro cuando se adentran en el monocultivo, como lo que ocurre con los hombres de La vorágine que Clemente Silva busca en vano, porque «Ni rastro de ellos. ¡Los devoró la selva!» (Rivera, 1997, p. 285). De este modo, el biólogo ve a los hombres perderse en esa tierra sin tierra:

El biólogo lo sigue a una distancia prudente, y el negro, con su traje azul metálico, se interna en el cañaveral que, bajo el sol agrio, a esa hora en la que no sopla el viento, arroja un fulgor despojado de cualquier entusiasmo, acostumbrado como está a predominar en el paisaje del valle, sumido en ese aire de derrota moral que tienen los que ganan siempre. El traje azul metálico desaparece entre las cañas verdes. El biólogo lo sigue. Pero cuando se inserta en el monocultivo ya no hay ni rastro del negro. El monocultivo niega el tiempo, lo cancela. Para el monocultivo no hay historia, ni hombres, solo eternidad, o sea, la nada absoluta. El monocultivo es la voluntad de Dios en la tierra. Una tierra sin tierra. El algoritmo divino que hace que todo sume cero para mayor gloria del Uno (Cárdenas, 2017, p. 89).

Estos signos desplegados en la novela de Rivera y en la narración de Cárdenas representan el cruce y las consecuencias de las políticas extractivas y las transformaciones delirantes del paisaje, una manera de representación de las crisis, del hombre consumido por el ecosistema que cree tener bajo control, además de que las consecuencias de estas transformaciones no son solo locativas, sino que se expanden como las pandemias y las plagas resultado de estas deformaciones. El diablo de las provincias extiende, pues, ese diálogo, en una escritura que captura la resistencia de los espacios. Esto se plasma de un modo similar en las afirmaciones hechas por Andermann (2008):

El paisaje, sugiero, es uno de los nodos principales a través de los cuales podemos pensar la intersección entre prácticas políticas y estéticas de la modernidad, prácticas del Estado, así como de su contestación por parte de disidencias de cuño «revolucionario» o «conservador». Si en el siglo XIX el paisaje pintoresco del naturalismo romántico fue sentando las bases iconográficas de los emergentes estados oligárquico-liberales, exportadores de materias primas, las transformaciones que fue sufriendo la forma paisaje a lo largo del siglo xx son a un mismo tiempo el índice de la crisis de este sistema político, económico y cultural y del fracaso persistente de trascender sus contradicciones fundamentales (p. 2).

Y es que, al final del libro, el biólogo es absorbido por el paisaje. Su gestión disciplinar, académica, queda postrada al servicio de la operación del monocultivo. Indicando, de paso, el fracaso de su discurso: ya no es el 
Paisaje y trance en tres obras de la narrativa latinoamericana contemporánea

naturalismo romántico, sino una especie de ambientalismo romántico que termina siendo tragado por la destrucción del paisaje.

\section{Mataderos, ganados y hombres}

Por último, aparece una narración donde el paisaje ha mutado a un estadio totalmente artificial, uno en el que la agroindustria ha despojado al paisaje anterior y lo ha convertido en una fábrica, que es considerada a su vez como la extensión del Matadero (1839) de Esteban Echavarría. En este caso, se hace referencia a una novela de la escritora brasilera Ana Paula Maia, De ganados y de hombres (2015). En la narración trazada exclusivamente por hombres y animales, «Hombres del ganado y la sangre» (p. 34), la autora lleva al extremo una trama sangrienta y brutal sobre la barbarie oculta en los procesos de producción de alimentos, exactamente sobre la producción de proteína animal. En el libro, uno de los tantos hombres debe aturdir a los animales en una caja (un box) y darles un golpe de gracia antes de que sean despedazados, y así su carne abastezca a una fábrica de hamburguesas. Sin embargo, la rutina atroz se «paraliza» cuando el ganado empieza a comportarse de manera extraña; primero con la rara desaparición y muerte de veintidós cabezas de ganado y con la contaminación del río cercano por donde empiezan a emerger peces muertos. A estos hechos le siguen el «suicidio» de otro lote de vacas. Una situación que llevará a la quiebra transitoria al matadero, donde los únicos favorecidos por las circunstancias «anormales» son los habitantes pobres del pueblo y los perros, que se alimentan de la carne de los animales muertos. En este marco se da una metamorfosis, en la que se hace visible la animalización de los humanos y la humanización de los animales. Un tránsito del paisaje en el que la carne del animal reemplaza el lugar que el humano tiene, deshaciéndose la división biopolítica que sostiene el asesinato normalizado de animales. Esta forma de metamorfosis sigue la idea que planteó Andermann (2011), sobre todo en la articulación de esta narración con la tradición literaria argentina, en la que los cuerpos populares son animalizados como mecanismo de control y ejercicio de poder sobre estos. Una tradición que puede rastrearse desde obras ya mencionadas como El matadero (1839) de Esteban Echeverría, hasta el pueblo animal que aparece en Tadeys (1994) de Osvaldo Lamborghini. Ahora bien, Ayala (2018) ofrece una interpretación sobre esta tradición:

En la época moderna, el célebre cuento «El matadero» (1839) de Esteban Echeverría puede leerse también bajo esta perspectiva. Ahí, el espacio físico de producción de carne exhibe cuerpos animales y cuerpos populares abiertos y abyectos, sucios y hambrientos. Hay una degradación y mezcla racial, cultural, de género y especie - negras, mulatas, indias, niños, perros, aves de carroña - enmarcada en la producción y la violencia. El pueblo es animalizado y bestializado, el matadero es el espacio de la violencia soberana (Giorgi, p. 132). «El matadero» da cuenta de la exposición del cuerpo popular animalizado a partir de una división biopolítica y política a la vez. La tradición literaria argentina del siglo xx es pródiga en estas figuras. Hay un pueblo animal en Osvaldo Lamborghini y también en «La fiesta del monstruo» de Jorge Luis Borges y Adolfo Bioy Casares. En todos ellos los animales son una figura política (pp. 17-18).

Esta relación hecha entre humanos y animales puede rastrearse también en otras narraciones latinoamericanas, 
Paisaje y trance en tres obras de la narrativa latinoamericana contemporánea

donde los animales y los humanos entran en conflicto como mecanismo de representación de la violencia económica derivada del colonialismo y la imposición del del capitalismo en la región. En esa vía, entonces, existe otro abanico de narraciones que pueden leerse dentro de esa perspectiva, que la novela de Ana Paula Maia retoma sobre todo por las escenas explícitas de explotación y crueldad con los animales que se registran en su narración. Si bien el espacio no es ya el espacio fronterizo y selvático, donde se desarrollan las narraciones de autores como Horacio Quiroga o Joao Guimarães Rosa, el lugar descrito, el paisaje alterado, como se ha mencionado, es un matadero que está anclado en una zona rural. Es decir, una frontera, última, entre los paisajes selváticos y el paisaje urbano. Un lugar donde el olor a muerte está instalado en todas partes: «Acá el olor a muerte se siente en todas partes» (Maia, 2015, p. 14). Un espacio de confluencia donde se dan una serie de metamorfosis entre los cuerpos, siendo estas las señas del delirio entre unos y otros. Animales que se «suicidan» y hombres que son asesinados como las cabezas de ganado que deben sacrificar. Como lo describe entonces Ayala (2018), los demás casos emblemáticos de la literatura latinoamericana donde los animales y humanos entran en conflicto son, entre muchos otros, los siguientes:

[...] los dos cuentos de metamorfosis humano/animal, enmarcados en un discurso modernizador y de expansión cultural: «Juan Darién» (1924) de Horacio Quiroga o «Meu tio o Iauaretê» (1950) de Joao Guimarães Rosa. En ambas narraciones, los sujetos populares transformados en animales salvajes (tigre y jaguar, respectivamente) se enfrentan a la violencia económica y expansiva de la civilización occidental. En estos relatos fantásticos, la alteración entre las fronteras de las especies y los cuerpos remite a la vida como la apertura entre el cuerpo, el espacio y el sentido, lo que se expresa a través de la tensión entre oralidad y escritura; ruido, sonido, gruñido y voz. La metamorfosis de los cuerpos en estos cuentos se produce en zonas selváticas de frontera en las que avanza la violencia colonial para instaurar el capitalismo. Como afirma Andermann las metamorfosis muestran la «continuidad de lo viviente que se enfrenta a la máquina antropológica occidental» (p. 21).

Ajustándose a este marco, y a esta tradición de narraciones, lo que se describe en la novela es una muestra de contigüidad y proximidad con la vida animal, que emerge como un «campo expansivo». Es por eso que, desde las primeras páginas en De ganados y de hombres, se lee una progresión de eventos espeluznantes que van marcando un tejido irregular dentro de las operaciones normales de una planta de sacrificio. Como se ha dicho, la presencia de las mujeres está suprimida en la narración, solo se retrata a un grupo de hombres desarrollar distintos trabajos en el matadero. Uno de ellos es Edgar Wilson, el encargado del aturdimiento de las vacas. Este es descrito como un asesino que solo ha encontrado oportunidades laborales matando animales — como una forma de continuidad a sus crímenes - ; sin embargo, en uno de los primeros pasajes, en el cual Wilson debe darle el golpe con la maza a uno de los animales, lo que se narra, en esa secuencia atroz, es un comportamiento distinto de la simple operación de sacrificio. De este modo, lo que hace él en su relación con los animales es un acto donde trata de salvarles el alma, como si el acto de la matanza fuera una liturgia entre el hombre y el animal:

La hilera de vacas y bueyes siempre es larga. Un empleado se encarga de abrir la compuerta y la vaca, que viene de la inspección y del baño, entra despacio, desconfiada, mirando a los costados. Edgar agarra la maza. El animal camina casi hasta donde está él. Edgar lo mira a los ojos y le acaricia la frente. La vaca golpea el piso con una de las 


\section{Paisaje y trance en tres obras de la narrativa latinoamericana contemporánea}

patas, sacude el rabo y resopla. Edgar silva y los movimientos de la vaca se destensan. Hay algo en ese silbido que hace que el ganado entre en un estado de soñolencia y quede íntimamente ligado a Edgar Wilson, entablándose de esa forma una confianza mutua. Con el pulgar manchado de cal, Edgar dibuja una cruz entre los ojos del rumiante y se aparta dos pasos hacia atrás. Es su ritual de aturdidor. Alza la maza y golpea, con precisión, la frente. Provoca un desmayo a causa de una hemorragia cerebral. La vaca, volteada en el suelo, sufre una seguidilla breve de espasmos hasta que se calma (Maia, 2015, p. 13).

Lo que se evidencia en esta secuencia del sacrificio es un comportamiento irregular, que se sale de la línea habitual, un quiebre en las operaciones y en el poder destructor y acumulativo en este tipo de manufacturas, en las que los cuerpos de los animales son sacrificados sin reparo. Edgar Wilson, además de marcar distancia y de establecer una relación distinta con los cuerpos sacrificados, los dota de una espiritualidad, intentando tener un tipo de redención para sí mismo y para con los animales en su destino cruel. Lo que hace él con esta operación delirante, dada sobre todo por el acto de confianza con los animales y sus líneas de comunicación, es una detención del avance capitalista, torciendo el relato de la acumulación con la vinculación de otros sentidos. Esa manera de sacrificio - la marca de la cruz - se constituye como una última oportunidad de redención y un vínculo entre las especies sacrificadas, que son ambas. A esto se refiere Andermann (2011) cuando habla de la continuidad de los vivientes:

La continuidad de lo viviente es el gran obstáculo con que se encuentra el avance capitalista, y contra la que vuelca su discurso de la especie en función de poder introducir un quiebre, una distancia, entre sociedad y naturaleza sometiendo a ésta última como objeto externo a su afán destructor y acumulativo, «cazando, matando, degollando» y que convierte a los hombres (en la mirada del niño-tigre) en una «raza sin redención» (p. 13).

Este pliegue no solo se da por las acciones de Edgar Wilson, sino que también está expresado en el hábitat compartido de los cuerpos sacrificados (el ganado) y el cuerpo de los sacrificadores (los hombres). Ambos viven en el mismo lugar, ambos están pasados por la sangre y el sacrificio. Lo que indica, además, que el cruce o la metamorfosis entre ellos no deviene de un acto mágico; por eso, la mutación es producto de un ensamble derivado de la vida en el matadero. Lo humano y lo animal, en estos lugares de sacrificio, pierden elementos que los diferencian. Ambos son uno solo en el matadero, rompiéndose así el espacio que busca poner distancia entre lo animal y lo humano que señaló Giorgi (2014). En el matadero, según este autor, se «busca aislar la vida eliminable, consumible, de la vida protegida, reforzar su distinción evitando que la muerte animal se mezcle, contagie e irrumpa en la vida de la comunidad» (2014, p. 137). Esto, en la novela de Maia, se evidencia en los elementos de convivencia entre el hombre y los animales, en los cuales son solo las «voces» y los «mugidos» los pueden dar una distinción:

Ambos recintos, el del ganado y el de los hombres, se ubican uno al lado del otro, medianera de por medio, y por un momento un mismo olor los ensambla. Solo las voces que vienen de un lado y los mugidos del otro alcanzan para distinguir a hombres de rumiantes (Maia, 2015, p. 21). 


\section{Paisaje y trance en tres obras de la narrativa latinoamericana contemporánea}

Y estos elementos no solo son reconocibles como dispositivos aleatorios entre humanos y animales, dado que también sufren otro tipo de dislocación en el cambio de norma, cuando Edgar Wilson decide asesinar a un compañero, Zeca, quien trabaja en turnos como aturdidor de los animales, pero con evidente distancia de lo hecho por el primero. A diferencia de lo hecho por Wilson en su ceremonia de sacrificio, a Zeca no le importa perforar las veces que sea necesario el cuerpo de los animales, destrozarlos y hacerlos «sufrir» sin piedad. De esta manera, lo que podría leerse como un acto simple de venganza y de justicia ante las malas acciones de Zeca, es en realidad un acto de metamorfosis, que se hace patente cuando Wilson decide matarlo con la misma herramienta de trabajo con la que sacrifica a los animales. Así los hombres, en este caso Zeca, pasan a ser los sacrificados, con el mismo tacto, la misma cruz y la misma herramienta. Luego, se deshace del cuerpo al mezclaro con los restos de sangre del ganado, dando paso así a una metamorfosis en la muerte, con la sangre:

Espera hasta que solo queda Zeca en el baño. Con la maza, su herramienta de trabajo, encaja un golpe preciso en la frente de muchacho, que cae al suelo entre terribles convulsiones y una serie de gemidos casi sin voz. Edgar Wilson dibuja una cruz antes de colgar el cadáver de Zeca y cubrirlo con una manta. Ni una sola gota de sangre se derramó. El suyo es un trabajo limpio. Al fondo del río, junto con restos de sangre y vísceras de ganado, esa noche es lanzado el cuerpo de Zeca, que, con el fluir de las aguas, y lo mismo que el río, acabará yendo a parar al mar (Maia, 2015, p. 22).

Esta representación del sacrificio humano, en el lugar del animal, se entiende además cuando Giorgi (2014) menciona a los mataderos como lugares de vida y muerte, ya que a partir de esta conexión en la que se borra toda distinción entre animal y humano, se da una mezcla de cuerpos en beneficio de las biopolíticas del capital, que en el caso de la narración de Maia se amplía a la fábrica de hamburguesas: «Allá en la fábrica de hamburguesas, la blancura refleja una paz que no existe, un relumbrón que enceguece la muerte. Todos son matadores, cada cual de su especie, ejecutando la función que les toca en su línea de sacrificio» (Maia, 2015, p. 39); esto es, a un lugar del proceso que está exento de la sangre o que por su asepsia ha sido desmarcado de la brutalidad. Esto, en palabras de Andermann (2011) sería un tipo de paisaje, una forma de ocultamiento del delirio original. Pero, incluso, la narración lo extiende más allá cuando conecta a los que matan y los que consumen los cuerpos: «Los que están para comer son muchos y comen sin saciarse nunca. Todos son hombres de sangre, los que matan y los que comen. Nadie es impune» (Maia, 2005, p. 107). Todo esto, pues, en torno a la noción central - la del sacrificio animal en el matadero-, donde los hombres y los animales mezclan sus cuerpos. De este modo, como lo advierte Giorgi (2014), los mataderos se vuelven espacios difusos, inciertos:

En el matadero no hay «humanos» y «animales», hay solamente cuerpos entre la vida y la muerte: sobre esta dislocación o desplazamiento piensan las biopolíticas del capital o del poder soberano justamente a partir de conexiones, contagios, mezclas de cuerpos. Los mataderos de la cultura son, entonces, instancias en las que se escenifica una corporalidad difusa, de contornos inciertos, donde la diferencia y la jerarquía entre humano y animal deja lugar a la distribución móvil, política, entre bios/zoe, es decir, entre cuerpos reconocibles políticamente y cuerpos abandonados y sacrificables: el cuerpo animal será la zona de indeterminación sobre la que se trazará esa distinción que, inevitablemente, permanecerá inestable, difusa y, por lo tanto, crítica, en la medida en que revoca todo ordenamiento fijo de cuerpos ( pp. 137-138). 
Así, el matadero es un lugar propicio para el delirio oculto del paisaje, donde «el olor a muerte se siente en todas partes» (Maia, 2015, p. 14). Esta sensación se transporta en la carne muerta, convertida en las hamburguesas que alimentan a los que consumen el producto sin reparo y olvidan su origen. Así, en el matadero se pierde, según lo dicho por Giorgi (2014), la falsa jerarquía entre los animales dominados, porque en la novela de Maia los cuerpos son usados y sacrificados en iguales condiciones, lo que de paso señala uno de los puntos claves donde se funda y desfonda el régimen de acumulación que expone Andermann (2011), es decir, la producción delirante del capital a la par que se destruye el paisaje.

\section{Conclusiones}

En consecuencia, lo expuesto en las tres novelas se inserta en esa tradición recuperada por Andermann (2011) de narraciones que representan una secuencia de crisis ambientales producto de la agroindustria y ganadería neoliberal. Si bien los mecanismos de representación no son directos y los géneros usados —el fantástico y el terror- disfrazan los peligros detallados, las derivaciones de los circuitos de la economía capitalista, que campean en el nuevo siglo y, a futuro, entran en relación con los personajes; ellos, como el ambiente, están siendo alterados, porque son parte de ese ecosistema intervenido. Lo que se puede inferir de estas narraciones es una prolongación de las economías de extracción y las degradaciones ambientales activas como agentes que operan en los relatos. La amenaza ya no es el encuentro entre los sujetos-personajes y su relación con el medio ambiente, sino que la representación que estas ficciones ofrecen son unos ecosistemas delirantes, con equilibrios maltrechos, productos de la instalación de monocultivos o mataderos. Como afirma Andermann (2011), estas serían unas narraciones cooptadas por las disfuncionalidades de la economía del capital. 


\section{Referencias bibliográficas}

1. Andermann, J. (2008). Paisaje: Imagen, entorno, ensamble. Orbis Tertius, 13(14), 1-7. http://www.memoria. fahce.unlp.edu.ar/art_revistas/pr.3749/pr.3749.pdf

2. Andermann, J. (2011). Tesis sobre la metamorfosis. Boletín del Centro de Estudios de Teoría y Crítica Literaria, $16,1-14$.

3. Andermann, J. (2018). Tierras en trance. Arte y naturaleza después del paisaje. Santiago: Metales Pesados.

4. Ayala Munita, M. (2018). Animales, personas, autómatas y espectros en América Latina. Revista de Humanidades, (38), 17-18. https://www.redalyc.org/jatsRepo/3212/321260113001/html/index.html

5. Cárdenas, J. (2017). El diablo de las provincias. Madrid: Periférica.

6. Espósito, R. (2008). Inmunitas. Protección y negación de la vida. Buenos Aires: Amorrortu.

7. Giorgi, G. (2014). Formas comunes. Animalidad, cultura, biopolítica. Buenos Aires: Eterna Cadencia.

8. Giorgi, G y Rodríguez, F. (2007). Ensayos sobre biopolítica. Excesos de vida. Buenos Aires: Paidós.

9. Lapolla, A. (2007). Argentina: sojización, toxicidad y contaminación ambiental por agrotóxicos. Revista BiodiversidadLa. https://www.biodiversidadla.org/Documentos/Argentina-sojizacion-toxicidad-ycontaminacion-ambiental-por-agrotoxicos

10. Lizcano, M. F. (2018). Colombia: la palma de aceite pone en jaque la flora y la fauna del Pacífico. Mongabay. https://es.mongabay.com/2018/11/colombia-palma-de-aceite-pacifico/

11. Maia, A. P. (2015). De ganados y de hombres. Buenos Aires: Eterna Cadencia.

12. Rivera, J. E. (1997). La vorágine. Bogotá: El Áncora Editores.

13. Schweblin, S. (2015). Distancia de rescate. Bogotá: Literatura Random House. 